\title{
Core Principles to Improve Primary Care Quality Management
}

\author{
Justin B. Mutter, MD, MSc, Winston Liaw, MD, MPH, Miranda A. Moore, PhD, \\ Rebecca S. Etz, PhD, Amanda Howe, MD, MEd, FRCGP, and \\ Andrew Bazemore, MD, MPH
}

Quality management in American health care is in crisis. Performance measurement in its current form is costly, redundant, and labyrinthine. Increasingly, its contribution to achieving the Quadruple Aim is under close examination, especially in the domain of primary care services, where the burden of measurement is heaviest. This article assesses the state of quality management in primary care in the United States, particularly the 2015 Medicare Access and Children's Health Insurance Program Reauthorization Act, in comparative perspective, drawing lessons from the Quality and Outcomes Framework in the United Kingdom. The health care delivery function specific to primary care is pivotal to crossing the quality chasm, yet prior efforts to improve the quality of this function have failed more often than succeeded. These failures are the result of quality programs unguided by core principles of primary care. Quality management in primary care requires a more disciplined approach, adherent to 4 foundational principles: optimizing holistic patient and population health; harnessing the Quadruple Aim as a dynamic whole; applying measurements as tools for quality, not outcomes of quality; and prioritizing therapeutic relationships. These principles serve as the foundation for a bridge to high-functioning primary care that will lead American health care closer to the Quadruple Aim. (J Am Board Fam Med 2018;31: 931-940.)

Keywords: Children's Health Insurance Program, Medicare, Population Health, Primary Health Care, Quality of Health Care

Quality management in American medicine is in crisis. While advances have been made since the publication of the Institute of Medicine's Crossing the Quality Chasm in 2001, ${ }^{1}$ both providers and

This article was externally peer reviewed.

Submitted 27 April 2017; revised 1 April 2018; accepted 3 April 2018.

From Department of Medicine, Center for Biomedical Ethics and Humanities, University of Virginia School of Medicine, Charlottesville, VA (JBM); Robert Graham Center, Washington DC (JBM, WL, AB); Department of Family and Community Medicine, University of Texas Health Science Center at Houston, Houston, TX (WL); Department of Family and Preventative Medicine, Emory University School of Medicine, Atlanta, GA (MAM); Department of Family Medicine and Population Health, Virginia Commonwealth University School of Medicine, Richmond (RSE); Department of Population Health and Primary Care, Norwich Medical School University of East Anglia, Norwich, UK (AH)

Funding: none.

Conflict of interest: none declared.

Corresponding author: Justin B. Mutter, MD, MSc, Division of General, Geriatric, Palliative and Hospital Medicine, Department of Medicine, Center for Biomedical researchers increasingly recognize that the effort to achieve large-scale quality improvement through reporting programs and performance measurement has produced lackluster or even injurious results. First, measurement has become atomistic. Over the last decade, the number of quality indicators has grown exponentially. According to the National Quality Measures Clearinghouse, there are now nearly 2000 publicly available indicators sponsored by over 100 health care institutions. ${ }^{2}$ Of these indicators, only a small fraction represent meaningful clinical outcomes and still fewer reflect patientoriented or patient-reported indicators. ${ }^{3}$ Second, measurement has become costly to the financial and social capital of health care institutions. Recent research has estimated that the per-physician cost

Ethics and Humanities, University of Virginia School of Medicine, P.O. Box 800758, Charlottesville, VA 22908 (E-mail: jbm4n@hscmail.mcc.virginia.edu). 
of quality reporting exceeds $\$ 40,000$ annually, requiring greater than 15 hours of total staff work weekly. ${ }^{4}$ Finally, despite the volume and cost of these measurements, their use has been of questionable benefit. A systematic review of pay-forperformance $(\mathrm{P} 4 \mathrm{P})$ programs linking quality reporting to financial remuneration, drawn from studies in several industrialized nations, suggested that $\mathrm{P} 4 \mathrm{P}$ has, on average, produced just $5 \%$ improvement in provider performance, with gains limited to select process-oriented measures. ${ }^{5}$ Whether quality measurement influences patient-centered outcomes, such as mortality, quality of life, and function, remains largely unknown.

Such dysfunction disproportionately affects the delivery of primary care services. Primary care providers shoulder a larger financial and administrative burden from quality reporting than do other practitioners. ${ }^{4}$ Accreditation, measurement, and incentive programs, such as the patient-centered medical home, can cost up to $\$ 115,000$ per provider, per year. ${ }^{6}$ The opportunity costs of such endeavors are substantial, fostering the perspective that measurement adversely impacts providers' ability to care for patients. In a recent national survey of primary care providers, fewer than a quarter of respondents expressed a "positive" view of current quality measurement requirements. ${ }^{7}$

Although primary care is at the epicenter of our crisis in quality management, it is also the source for its resolution. Extensive research has shown that high-functioning primary care is associated with better population health, at lower cost, with less inequality in health outcomes between groups. ${ }^{8}$ The delivery function specific to primary care, widely recognized as the "4C's" of comprehensive services, patient-centered continuity of care, accessible first-contact in care, and coordination of care, ${ }^{9}$ is critical to achieving the Quadruple Aim. ${ }^{10}$ Primary care must, therefore, serve as the bridge across the quality chasm, which has narrowed yet persisted over time, with worrisome inequalities and geographic variations in care. ${ }^{11}$ In this context, getting quality measurement right for primary care is imperative.

In this article, we argue that despite the ample evidence of inadequacies in contemporary quality programs for primary care, policy makers and regulatory agencies have yet to appropriately redesign metric systems. As an illustration of this failure to adapt, we review the research literature on the
United Kingdom's Quality and Outcomes Framework (QOF) for primary care, noting several disconcerting results. Turning to the US context, we find that the structure of the 2015 Medicare Access and Children's Health Insurance Program Reauthorization Act (MACRA) recapitulates the QOF's flaws and, therefore, risks deepening the quality crisis. We maintain that the persistence of largely unmodified performance measurement programs for primary care over the last decade is due to these programs' neglect of guiding principles. Historically, quality reporting has been a cart-before-thehorse phenomenon, where we are "measuring the measurable," 12 without assiduous attention to the means and ends of measurement. The science of primary care, however, requires a more deliberate, foundational approach to quality. As a corrective, we outline 4 core principles for quality management in primary care.

\section{Looking Back, Looking Forward: MACRA Through the Lens of the QOF}

The acceleration toward value-based payment for US primary care has an important counterpart in the United Kingdom. In 2004, the United Kingdom's National Health Service (NHS) initiated the QOF, which remains the most ambitious, comprehensive $\mathrm{P} 4 \mathrm{P}$ program for primary care in the world. Now into its second decade, the QOF has linked as much as $25 \%$ of general practitioners' income to an extensive collection of quality metrics for up to 20 chronic conditions. ${ }^{13}$ Over the last few years, several reviews of the QOF's impact have been published, and its precise future is under debate. ${ }^{14}$ Although limited by the lack of an adequate control group against which to compare its effects on health care in the United Kingdom, ${ }^{15}$ the QOF, implemented in a highly integrated health system with patients enrolled in primary care, under a single payer system, with a unified reporting system, is an experiment in quality management from which invaluable lessons can be learned. ${ }^{16}$

By all accounts, the QOF has been modestly effective in achieving its targets. Overall, metric achievement rates improved consistently, and disease-specific reviews have found advances in chronic disease management, such as with diabetes. ${ }^{13-21}$ These gains have narrowed some population-level inequalities between populations in the delivery of clinical standards of care, although it is 
important to note that there was no corresponding narrowing of inequalities in health outcomes in the United Kingdom. ${ }^{21}$ Nearly all reviews, however, report a plateau in the curve of improvement after the first year or 2 of adoption, suggesting once the lower limit of a target had been satisfactorily reached, most practices did not extend the mark.

Unfortunately, these achievements came with significant costs. Research has indicated that nonincentivized quality indicators languished in comparison to the QOF measurements, raising concern that despite accounting for only a quarter of practitioners' income, the process of meeting QOF metrics required a majority of their time. Furthermore, as the "doctor's gaze" focused on the QOF, ${ }^{13}$ patients' views were at risk of being neglected. Research found little to no improvement in patients' experiences of care ${ }^{19}$ and has noted the dominance of a biomedical approach to patient encounters, with concomitant neglect of more holistic care. $^{22}$

Finally, there is no clear evidence for correlation between quality improvement under the QOF and patient-centered outcomes. Although some modeling has suggested a possible minor mortality benefit, this suggestion has not been consistently corroborated by observational studies of death rates or other patient outcomes, such as avoidable hospitalizations. ${ }^{13}$ Only one of the clinical indicators used throughout the years of the QOF is a "health outcome" instead of an "intermediate outcome" or clinical process: documenting that a patient with epilepsy has been seizure-free for at least 12 months. ${ }^{18}$ Notably, there is some evidence that acute care use for this disease domain has improved under the QOF. ${ }^{17}$

In response to the perceived inability of the QOF to impact population health, the NHS is experimenting with alternative contracts and payment models. For example, as P4P financing through the QOF has diminished, providers and policy makers in the United Kingdom have developed "capitated outcome-based and incentivized contracts." These new contracts aim to correct the shortfalls of other value-based purchasing programs by focusing on patient-oriented outcomes, longer-term contracts to meet those outcomes, and capitated payments. ${ }^{23}$ Although no peer-reviewed research on their impact has been published, case reports have shown promise. ${ }^{24}$ Such contracts are just one potential tool in the hands of clinical com- missioning groups, the general practitioner-led, financial and administrative bodies established by the Health and Social Care Act of 2012 tasked with management of NHS provider contracts at the local levels. The work of clinical commissioning groups has been compared with that of accountable care organizations in the United States ${ }^{25}$; however, their potential impact on quality management and patient outcomes in the United Kingdom has yet to be determined.

The NHS is engaged in adaptive learning from the shortcomings of the QOF, whereas many quality programs in the US continue to build on its flawed structure. A central mechanism for achieving the Centers for Medicare \& Medicaid Services' (CMS) goal of tying $90 \%$ of all expenditures to quality or value by $2018,{ }^{26}$ MACRA is an exemplary case in point. Among other provisions, MACRA includes a process for streamlining prior quality measurement methods into a single scoring system for the Merit-Based Incentive Payment System (MIPS) by 2019. Providers will be judged across 4 domains, which include quality of care, resource use, advancing care information (or the meaningful use of electronic health records), and clinical practice improvement activities. Top performers will receive positive adjustments to Medicare Part B rates while the lowest performers will be negatively adjusted. ${ }^{27}$ Because MIPS will become the default Medicare payment system for all primary care providers who do not qualify for an Advanced Alternative Payment Model, a substantial majority of primary care practices caring for Medicare patients will be paid through MIPS.

Although MACRA was hailed initially, several concerns have already surfaced during its early implementation. ${ }^{28}$ First and most importantly, MACRA's aim to improve care is highly imprecise, without clearly defined objectives for primary care quality. Primary care providers select 6 measures to report (out of approximately 50 to 60 options), at once far fewer and more arbitrary than the 33 metrics required for accountable care

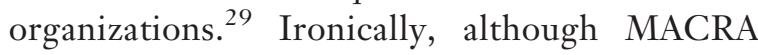
purports to restructure payment toward value, it is substantially more vague than the QOF in its anticipated achievements. If half of primary care practices choose 6 different metrics from the other half, how can their outcomes be appropriately compared and evaluated? Metric options for primary care in MACRA, nonetheless, still mirror the 
disease-specific, process-oriented design of the QOF. Because of this design, MACRA also risks widening health disparities rather than improving population health. MIPS measures focus narrowly on officebased clinical effectiveness, neglecting other features of comprehensive primary care services, including access, patient experience, social determinants of health, and interpersonal care. ${ }^{30}$

In summary, past lessons from the QOF and contemporary lessons from MACRA are at least threefold. First, without an overarching strategy for improving health, $\mathrm{P} 4 \mathrm{P}$ programs in primary care may use successful tactics, but disease-specific and process-oriented tactical targets do not necessarily lead to victory in the battle for population health. Second, all quality schemes have opportunity costs and unintended consequences that may significantly offset potential benefits. ${ }^{31}$ Although this fact is well known, it is nevertheless rare that such costs are incorporated into metric design and implementation. Third, current modalities for risk adjustment in quality measurement are mediocre at best. ${ }^{32}$ How P4P can widen rather than narrow health disparities has been well documented..$^{33}$ The results of the QOF and the inadequate design of MACRA show that without an appropriate adjustment for social risk, $\mathrm{P} 4 \mathrm{P}$ in primary care has the potential to transfer resources from providers treating high-risk patients to those treating low risk ones. $^{29}$

\section{Four Foundational Principles of Quality Management for Primary Care}

The worrisome deficiencies of the QOF and MACRA — and, in fact, the broader crisis of quality management in health care throughout many industrialized nations- have not arisen by accident. Much of the criticism of past and current quality schemes focuses on errors of commission: for example, failure to choose the right metrics ${ }^{34-35}$; neglect of provider input and wellness ${ }^{36-37}$; and regulatory preference for linear rather than complex systems. ${ }^{38}$ While we find many of these concerns to be salient, they obviate a more fundamental error of omission in primary care quality management: the absence of organizing principles to guide its optimization. To avoid the propensity to "measure the measurable," P4P and other quality programs in primary care must design and evaluate metrics with principles commensurate with the science of primary health care. Using the metaphor of a foundation on which the bridge to quality should be built, we propose 4 indispensable principles for quality management in primary care (Table 1 ).

To demonstrate the usefulness of our principles, we introduce a case study of a typical, but fictional patient followed by a primary care team. Mr. Jones is a 55 year old living with diabetes, high blood pressure, obesity, and mild chronic obstructive pulmonary disease, who continues to smoke several cigarettes daily. His primary care team follows 3 common disease-specific quality metrics in his care: blood pressure target less than 140 systolic over 90 diastolic, hemoglobin A1c levels less than 9\%, and documentation of smoking cessation counseling. Annually over a period of 3 years, his care team reports his hemoglobin $\mathrm{A} 1 \mathrm{c}$ is $6.5 \%, 7.5 \%$, and $8.5 \%$. His blood pressure readings vary somewhat but are typically just below the upper target limit. Despite brief behavioral counseling for his tobacco abuse received every year, he is unable to stop smoking. During these 3 years, the factory where he has held a part-time job closes, and he encounters financial difficulty with food and housing insecurity. He is rapidly gaining weight and experiences clinical depression. Consider now the marked difference between the documented narrative suggested by the 3 quality metrics and the lived narrative of Mr. Jones and his care team. Unguided by primary care's foundational principles of quality, the metrics miss critical concerns, including worsening diabetes control, weight gain, the hazards of ongoing tobacco abuse, and declining psychosocial determinants of health. The metrics are artificial

\section{Table 1. Four Foundational Principles for Quality Management in Primary Care}

\begin{tabular}{|c|c|c|}
\hline $\begin{array}{l}\text { Principle } 1 \text { (Cornerstone): The singular } \\
\text { objective of quality management in primary } \\
\text { care is to improve the health of patients and } \\
\text { populations. }\end{array}$ & A Bridge Across the Chasm & $\begin{array}{l}\text { Principle } 3 \text { : Measurements are tools for quality, } \\
\text { not outcomes of quality. }\end{array}$ \\
\hline $\begin{array}{l}\text { Principle 2: The Quadruple Aim is a dynamic } \\
\text { whole, not a sum of its parts. }\end{array}$ & & $\begin{array}{l}\text { Principle 4: Quality outcomes in primary care } \\
\text { depend on therapeutic relationships. }\end{array}$ \\
\hline
\end{tabular}


and largely irrelevant to the "whole" patient; the medical record reflects both a "virtual quality" and a virtual reality. ${ }^{39}$ Although hitting its targets, Mr. Jones's care team has risked missing the point.

In what follows, we outline our 4 principles of quality measurement for primary care and discuss how their consistent application might transform metric systems, all the while keeping patients like Mr. Jones in mind. No longer should the practices of quality management be constructed without rigorous adherence to these foundational principles.

\section{Principle 1: The Singular Objective of Quality Management in Primary Care is to Improve the Health of Patients and Populations}

Several years ago, Stange and Ferrer ${ }^{40}$ defined the "paradox of primary care": at the disease-specific level, primary care providers tend to score unimpressively on quality metrics, yet at the population level, their work is strongly associated with high quality and improved patient outcomes. The history of science and medicine has shown that a paradox only persists when the paradigm supporting it is flawed. ${ }^{41}$ The paradigm for quality management in primary care has relied on diseasespecific, biomedical, and process-oriented metrics. This old paradigm is inconsistent with primary care's focus on whole-person health, and, as a result, patient and population outcomes have not improved; patient experiences of care are stagnant; and quality reporting has become costly. The above principle offers a new paradigm attuned to holistic person-centered and population-based care. ${ }^{42}$ Adherence to this first principle will be particularly essential in the context of the epidemiologic prevalence of multimorbidity (of which Mr. Jones is typical) and the demographic growth of the geriatric population; precariously little is known about how to accurately and effectively measure quality in these groups. ${ }^{43} \mathrm{We}$ consider this principle to be the cornerstone of our foundation; without it, the others will not be sustained.

\section{Principle 2: The Quadruple Aim is a Dynamic Whole, Not the Sum of Its Parts}

In the original conception of the Triple Aim, each vertex on the triangle depends on, and is affected by, the others. ${ }^{44}$ The goal of achieving substantial improvements in population health, patients' experiences of care, and health expenditures, therefore, cannot be reached piecemeal. To this initial trian- gle, primary care has added a fourth point of providers' experiences of care. ${ }^{10}$ Whether evolutionary or revolutionary in scope, health policies must be judged by their impact on the Quadruple Aim in its entirety. If we "measure the measures" in the United States and the United Kingdom, despite nearly 15 years of various measurement programs, there is no clear evidence that our efforts have moved us significantly closer to the Quadruple Aim. ${ }^{45}$ In neglect of this principle, quality programs in primary care have overemphasized the dissemination and collection of metrics, while largely ignoring their impact on costs and providerpatient experiences. This neglect is one of the sources of our current quality crisis.

\section{Principle 3: Measurements Are Tools for Quality, Not Outcomes of Quality}

The very act of measuring poses significant challenges, particularly in a context where primary care providers are often juggling an array of medical and psychosocial concerns at once. A measurement, by definition, is a snapshot in time and space and is, therefore, limited in its capacity to capture a trajectory, to account for complexity, and to reflect high-risk environments. The dilemma of Mr. Jones and his care team is a case in point; the snapshots in his medical record cannot effectively address the development of an intricate web of concerns over time. In fact, patient outcomes are more like "vectors" than discrete points. ${ }^{46}$ Measurements, therefore, must be viewed as just 1 tool in an extensive toolkit for quality improvement. Historically, however, they have been used as centerpieces that crowd out other modalities for quality assurance. Future quality programs for primary care must understand that measurements are imperfect proxies for outcomes; as such, policy makers and regulatory agencies must be wary of mistaking points for trajectories.

\section{Principle 4: Quality Outcomes in Primary Care Depend on Therapeutic Relationships}

Primary health care, at its core, relies on highfunctioning relationships characterized by trust and professionalism. Like the QOF in the United Kingdom, rewards, penalties, and requirements now dominate quality management in US primary care. These programs are designed and administered by third parties remote from providers, patients, and their communities. Consistent with the 
old biomedical, process-oriented paradigm, these forms of extrinsic motivation often sap providers' intrinsic drive to improve patient outcomes and can lead to "gaming" of the system. ${ }^{47}$ Despite robust documentation of the limitations of extrinsic programs, such as $\mathrm{P} 4 \mathrm{P},{ }^{4}$ and despite compelling evidence that intrinsic motivation improves patient outcomes, ${ }^{45,47-49}$ policymaking has focused predominantly on the former at the expense of the latter. Even programs like the Physician Quality Reporting System in the United States (now assimilated into MACRA), which attempts to integrate intrinsic motivation through providers' free choice of metrics, remains extrinsic in design and implementation. ${ }^{50}$ These approaches risk pitting what Donabedian called the "technical" aspects of quality against its "interpersonal" aspects, which he noted was a "vitally important element" for patient outcomes. ${ }^{51}$ Furthermore, the emphasis on technical, quantitative, and extrinsic design for quality improvement has often eclipsed patient roles in defining and measuring quality of care. ${ }^{52} \mathrm{Mr}$. Jones may have a very different set of priorities for his care, for example, alleviating his social stressors as a step toward diabetes control and smoking cessation, than the set of quality metrics his care team is required to assess. In all, our near-exclusive focus on extrinsic programs, quality management's version of "strangers at the bedside," provider-patient and provider-community relation- ships in the quest for quality improvement. In the domain of primary care, this is a risk too great. Our fourth principle does not remove the need for external standards, but recognizes that the motivation to achieve those standards must increasingly come from within rather than from without.

\section{From Principles to Practices: Building the Bridge Up from Its Foundation}

These 4 principles are primary. As regional and national conversations about the future of quality management evolve, they must be forethoughts, not afterthoughts. While reformist attempts to apply complexity science and the "business of health care" to quality management are welcome,${ }^{38,54}$ they will fail if not rigorously guided by primary care principles. Consider again the case of Mr. Jones, this time in the context of these principles. With increasing costs and prevalence of multimorbidity, a "whole person health" focus for patients like Mr. Jones would lead to less disease-specific and more comprehensive measurable outcomes, such as quality of life and mortality. ${ }^{55}$ Furthermore, to achieve the Quadruple Aim in Mr. Jones's care, his primary care team must address the social determinants of health and well-being. ${ }^{56}$ Note here the synergy between the application of all 4 principles: if performance measurement moves upstream to include complex psychosocial determinants of health and outward to include patient-centered and patient-

Table 2. Selected Practical Applications of Principles for Primary Care Quality

\begin{tabular}{|c|c|}
\hline Principles & Practices \\
\hline $\begin{array}{l}\text { Principle 1: The singular objective of quality measurement in } \\
\text { primary care is to improve the health of patients and } \\
\text { populations. }\end{array}$ & $\begin{array}{l}\text { Translating patient-centered and patient-reported outcomes } \\
\text { from research into clinical practice }{ }^{58} \\
\text { Applying population health metrics } \\
\text { Designing appropriate risk adjustments for the social } \\
\text { determinants of health }\end{array}$ \\
\hline $\begin{array}{l}\text { Principle 2: The Quadruple Aim is a dynamic whole, not a } \\
\text { sum of its parts. }\end{array}$ & $\begin{array}{l}\text { Anticipating financial, social capital, and opportunity costs } \\
\text { of measurement schemes } \\
\text { Harnessing patient and provider experiences of care as core } \\
\text { metrics } \\
\text { Optimizing electronic medical records to simplify } \\
\text { measurement and reporting, }{ }^{59} \text { accurately reflecting the } \\
\text { "lived narrative" of patient and provider }\end{array}$ \\
\hline $\begin{array}{l}\text { Principle } 3 \text { : Measurements are tools for quality, not } \\
\text { outcomes of quality. }\end{array}$ & $\begin{array}{l}\text { Extending reporting periods from one to three years } \\
\text { Improving parsimony in measurement sets }\end{array}$ \\
\hline $\begin{array}{l}\text { Principle 4: Quality outcomes in primary care depend on } \\
\text { therapeutic relationships. }\end{array}$ & $\begin{array}{l}\text { Decentralizing authority over metrics } \\
\text { Prioritizing intrinsic over extrinsic quality management } \\
\quad \text { systems } \\
\text { Sharing decision making over health goals }{ }^{38} \\
\text { Integrating psychosocial and community interventions into } \\
\quad \text { quality outcomes }\end{array}$ \\
\hline
\end{tabular}


reported outcomes, then primary care practices will have a greater opportunity to innovate at the intersection of clinical and community care. Unencumbered by certain arbitrary and artificial extrinsic measures, his primary care team can prioritize relationships and harness intrinsic motivation, working alongside him to improve his health and reach his own stated goals. While the design and implementation of person-centered and population health metrics for primary care remains in its infancy, such metrics may resolve problems inherent in surrogate biomarkers (eg, blood pressure), such as statistical reliability and year-to-year variation. ${ }^{57}$ These metrics may also, therefore, better capture patient and population outcome vectors, eschewing the unpredictability of discrete points.

These are just a few ways in which our 4 foundational principles can begin to build a primary care bridge across the quality chasm. Table 2 outlines select practices commensurate with these principles that future systems of quality management can incorporate. As with Mr. Jones, many of these practices are consistent with multiple principles at once.

\section{Conclusion: More Than a Set of Metrics_-Primary Care Quality as a Principled System}

The eminent historian of American medicine Charles Rosenberg once remarked that in modern systems of medical care, it "is almost as though the disease, not its victim, justifies treatment." ${ }^{\prime 1}$ The same, unfortunately, can be said for the current state of quality management in primary care. To transform this paradigm, we have delineated a set of foundational principles essential, although not unique, to primary care systems. As our principles suggest, "systems" is a keyword here. Although multistakeholder efforts such as the Core Measure Set for Primary Care and the Patient-Centered Medical Home are important, ${ }^{62}$ quality in primary care involves so much more than what metrics we choose and our actions toward meeting them. Quality management requires the alignment of principles across entire systems of care. Some of the most successful primary care programs over the last decade, evaluated through the lens of the Quadruple Aim, have sought precisely this alignment. The Community Aging in Place: Advancing Better Living for Elders (CAPABLE) program, funded by the Center for Medicare and Medicaid Innovation (CMMI), has focused on shared goal-setting and improved quality of life metrics for adults with functional deficits and complex psychosocial needs. In addition to nursing and occupational therapy services, CAPABLE intervenes in the social determinants of health with home repair services. Program results have yielded substantial cost savings, improvement in person-centered quality metrics, and high patient satisfaction with care experiences, ${ }^{63-65}$ all dynamic components of the Quadruple Aim. Similarly, programs in homebased primary care such as Independence at Home (IAH), also funded by CMMI, have implemented less disease-specific and more patientcentered outcome metrics, such as admissions for ambulatory-sensitive conditions and documentation of patient goals of care. ${ }^{66}$ Multidisciplinary services are systematically aligned with these quality goals, with 24-hour clinician availability and complex medication management. ${ }^{67} \mathrm{IAH}$ evaluations have been impressively consistent with the Quadruple Aim, with high-quality performance and estimated cost savings per beneficiary of approximately 10 times that of participants in pioneer accountable care organizations. ${ }^{66}$

The bridge to quality for primary care looks a lot more like CAPABLE and IAH than the QOF and MACRA. From the patient-centered medical home to CMMI's Comprehensive Primary Care Plus initiative, the reform of quality management according to the 4 foundational principles of primary care quality is urgent. Like the Quadruple Aim, these principles are interrelated and synergistic. It is time to put the horse before the cart and guide our system toward quality outcomes for all.

To see this article online, please go to: http://jabfm.org/content/ 31/6/931.full.

\section{References}

1. Institute of Medicine. 2001. Crossing the Quality Chasm: A New Health System for the 21st Century. Washington, D.C.: National Academy Press; 2001.

2. Agency for Healthcare Research and Quality. National quality measures clearinghouse home page. Available from: https://www.qualitymeasures.ahrq. gov. Accessed March 22, 2018.

3. Porter ME, Larsson S, Lee TH. Standardizing patient outcomes measurement. N Engl J Med 2016; 374:504-7.

4. Casalino LP, Gans D, Weber R, et al. US physician practices spend more than $\$ 15.4$ billion annually to 
report quality measures. Health Aff (Millwood) 2016;35:401-6.

5. Eijkenaar F, Emmert M, Scheppach M, Schöffski O. Effects of pay for performance in health care: a systematic review of systematic reviews. Health Policy 2013;110:115-30.

6. Magill MK, Ehrenburger D, Scammon DL, et al. The cost of sustaining a patient-centered medical home: experience from 2 states. Ann Fam Med 2016; 13:429-35.

7. Ryan J, Doty MM, Hamel L, Norton M, Abrams MK, Brodie M. Primary care providers' views of recent trends in health care delivery and payment. The Commonwealth Fund. Available from: http:// www.commonwealthfund.org/publications/issuebriefs/2015/aug/primary-care-providers-viewsdelivery-payment. Published August 5, 2015. Accessed March 22, 2018.

8. Starfield B, Shi L, Macinko J. Contribution of primary care to health systems and health. Milbank Q 2005;83:457-502.

9. Starfield B. Primary care: concept, evaluation, and policy. New York: Oxford University Press; 1992.

10. Bodenheimer T, Sinsky C. From Triple to Quadruple Aim: care of the patient requires care of the provider. Ann Fam Med 2014;12:573-6.

11. Agency for Healthcare Research and Quality. 2015 National healthcare quality and disparities report and 5 th anniversary update on the national quality strategy. Available from: http://www.ahrq.gov/sites/ default/files/wysiwyg/research/findings/nhqrdr/ nhqdr15/2015nhqdr.pdf. Published April 2016. Accessed March 22, 2018.

12. Starfield B, Mangin D. An international perspective on the basis of pay for performance. Qual Prim Care 2008;18:399-404.

13. Roland M, Campbell S. Successes and failures of pay for performance in the United Kingdom. N Engl J Med 2014;370:1944-9.

14. Forbes LJL, Marchand C, Doran T, Peckham S. The role of the quality and outcomes framework in the care of long-term conditions: a systematic review. Br J Gen Pract 2017;67:e775-e784.

15. Steel N, Willems S. Research learning from the UK Quality and Outcomes Framework: a review of existing research. Qual Prim Care 2010;18:117-25.

16. Doran T, Roland M. Lessons from major initiatives to improve primary care in the United Kingdom. Health Aff (Millwood) 2010;29:1023-9.

17. Gilliam SJ, Siriwardena AN, Steel N. Pay-for-performance in the United Kingdom: impact of the quality and outcomes framework-a systematic review. Ann Fam Med 2012;10:461-8.

18. Gillam S, Steel N. The quality and outcomes framework-where next? BMJ 2013;346:f659.

19. Llanwarne NR, Abel GA, Elliott MN, et al. Relationship between clinical quality and patient experience: analysis of data from the English quality and outcomes framework and the national gp patient survey. Ann Fam Med 2013;11:467-72.

20. Langdown C, Peckham S. The use of financial incentives to help improve health outcomes: is the quality and outcomes framework fit for its purpose? A systematic review. J Public Health (Oxf) 2013;36: 251-8.

21. Dixon A, Khachatryan A, Wallace A, Peckham S, Boyce T, Gillam S. The quality and outcomes framework: does it reduce health inequalities? London: National Institute for Health Research Service Delivery and Organisation Programme; 2010. Available from: http://www.netscc.ac.uk/hsdr/files/project/ SDO_FR_08-1716-207_V01.pdf. Accessed March 22, 2018.

22. Checkland K, Harrison S. The impact of the QOF of practice organization and service delivery. In: Gillam $\mathrm{S}$, Siriwardena N, editors. The quality and outcomes framework: QOF-transforming general practice. Abingdon: Radcliff Publishing, Ltd.; 2011.

23. Hicks N, Bell D. English developments in valuebased care: the beginnings of a revolution? Health Affairs Blog. Available from: http://healthaffairs.org/ blog/2016/03/16/english-developments-in-valuebased-care-the-beginnings-of-a-revolution/. Published March 16 2016. Accessed March 22, 2018.

24. Corrigan P, Hicks N. What organisation is necessary for commissioners to develop outcomes based contracts? The COBIC case study. October 2012. Published October 2012. Accessed March 22, 2018.

25. Noble DJ. Accountable care organizations and clinical commissioning groups face an uncertain challenge for improving public health. J Public Health Res 2012;1:113-6.

26. Centers for Medicare \& Medicaid Services. Better care. Smarter spending. Heathier people: paying providers for value, not volume. Available from: https://www.cms.gov/newsroom/fact-sheets/bettercare-smarter-spending-healthier-people-payingproviders-value-not-volume. Published January 2015.

27. Centers for Medicare \& Medicaid Services. Quality payment program executive summary. Available from: https://qpp.cms.gov/docs/QPP_Executive_ Summary_of_Final_Rule.pdf. Published 2016.

28. Senate Finance Committee. Medicare Access and CHIP Reauthorization Act of 2015: ensuring successful implementation of physician payment reforms. Available from: https://www.finance.senate.gov/imo/ media/doc/26671.pdf. Published July 2016. Accessed March 22, 2018.

29. McWilliams JM. MACRA: big fix or big problem? Ann Intern Med 2017;167:122-4.

30. Eggleton K, Liaw W, Bazemore A. Impact of gaps in merit-based incentive payment system measures on marginalized populations. Ann Fam Med 2017;15: 255-7.

31. Baker DW, Qaseem A. Evidence-based performance 
measures: preventing unintended consequences of quality measurement. Ann Intern Med 2011;155: 638-40.

32. Assistant Secretary for Planning and Evaluation. Social risk factors and performance under Medicare's value-based purchasing programs. Available from: https://aspe.hhs.gov/system/files/pdf/253971/ ASPESESRTCfull.pdf. Published 2016. Accessed March 22, 2018.

33. Casalino LP, Elster A, Eisenberg A, Lewis E, Montgomery J, Ramos D. Will pay-for-performance and quality reporting affect health care disparities? Health Aff (Millwood) 2007;26:w405-14.

34. Meyer GS, Nelson EC, Pryor DB, et al. More quality measures versus measuring what matters: a call for balance and parsimony. BMJ Qual Saf 2012;21: 964-8.

35. Asch SM, Kerr EA. Measuring what matters in health: lessons from the Veterans Health Administration state of the art conference. J Gen Intern Med. 2016;31:S1-2.

36. Reinertsen JL, Gosfield AG, Rupp W, Whittington JW. Engaging physicians in a shared quality agenda. IHI innovation series white paper. Cambridge, MA: Institute for Healthcare Improvement; 2007.

37. Reuben DB, Sinsky CA. From transactional tasks to personalized care: a new vision of physicians' roles. Ann Fam Med 2018;16:168-70.

38. Young RA, Roberts RG, Holden RJ. The challenges of measuring, improving, and reporting quality in primary care. Ann Fam Med 2017;15:175-82.

39. Goitein L. Virtual quality: the failing of public reporting and pay-for-performance programs. JAMA Int Med 2014;174:1912-13.

40. Stange KC, Ferrer RL. The paradox of primary care. Ann Fam Med 2009;7:293-99.

41. Kuhn TS. The structure of scientific revolutions, $3 \mathrm{rd}$ ed. Chicago: University of Chicago Press; 1996.

42. Starfield B. Is patient-centered care the same as person-focused care? Perm J 2011;15:63-9.

43. Boyd CM, Darer J, Boult C, Fried LP, Boult L, Wu AW. Clinical practice guidelines and quality of care for older patients with multiple comorbid diseases: implications for pay for performance. JAMA 2005; 294:716-24.

44. Berwick DM, Nolan TW, Whittington J. The triple aim: care, health, and cost. Health Affairs 2008;27: 759-69.

45. Herzer KR, Pronovost PJ. Physician motivation: listening to what pay-for-performance programs and quality improvement collaboratives are telling us. Jt Comm J Qual Patient Saf 2015;41:522-8.

46. Starfield B. Measurement of outcome: a proposed scheme. Milbank Q 2005;83:1-11.

47. Berenson RA, Rice T. Beyond measurement and reward: methods of motivating quality improve- ment and accountability. Heath Serv Res 2015;50: 2155-86.

48. Wynia MK. The risks of rewards in health care: how pay-for-performance could threaten, or bolster, medical professionalism. J Gen Intern Med 2009;24:884-7.

49. Pronovost PJ, Bo-Linn GW. Preventing patient harms through systems of care. JAMA 2012;308: 769-70.

50. Conway PH, Cassel CK. Engaging physicians and leveraging professionalism: a key to success for quality measurement and improvement. JAMA 2012;308:979-80.

51. Donabedian A. The quality of care: how can it be assessed? JAMA 1988;260:1743-8.

52. Xu Y, Wells PS. Getting (along) with the guidelines: reconciling patient autonomy and quality improvement through shared decision making. Acad Med 2016;91:925-9.

53. Rothman, DJ. Strangers at the bedside: a history of how law and bioethics transformed medical decision making, 2nd ed. New York: Aldine de Gruyter, 2011.

54. Brook RH. The end of the quality improvement movement: long live improving value. JAMA 2010; 304:1831-32.

55. Smith SM, Wallace E, Salisbury C, Sasseville M, Bayliss E, Fortin M. A core outcome set for multimorbidity research (COSmm). Ann Fam Med 2018; 16:132-8.

56. Devoe JE, Bazemore AW, Cottrell EK, et al. Perspectives in primary care: a conceptual framework and path for integrating social determinants of health into primary care. Ann Fam Med 2016;14:104-8.

57. Asch DA, Werner RM. Paying for performance in population health: lessons from health care settings. Prev Chronic Dis 2010;7:A98.

58. Basch E, Torda P, Adams K. Standards for patientreported outcome-based performance measures. JAMA 2013;310:139-40.

59. DiAngi YT, Lee TC, Sinsky CA, Bohman BD, Sharp CD. Novel metrics for improving physician fulfillment. Ann Intern Med 2017;167:740-1.

60. Madara JL, Bukhart J. Professionalism, self-regulation, and motivation: how did health care get this so wrong? JAMA 2015;313:1793-4.

61. Rosenberg CE. The tyranny of diagnosis. Milbank Q 2002;80:237-60.

62. Centers for Medicare and Medicaid Services. Consensus core set: ACO and PCMH/primary care measures. Available from: https://www.cms.gov/Medicare/Quality-Initiatives-Patient-AssessmentInstruments/QualityMeasures/Downloads/ACOand-PCMH-Primary-Care-Measures.pdf. Published February 2016. Accessed March 22, 2018.

63. Szanton SL, Thorpe RJ, Boyd C, et al. Community aging in place. Advancing better lives for elders: a bio-behavioral-environmental intervention to improve function and health-related quality of life in disabled older adults. J Am Geriatr Soc 2011;59: 2314-20. 
64. Szanton SL, Leff B, Wolff JL, Roberts L, Gitlin LN. Home-based care program reduces disability and promotes aging in place. Health Aff (Millwood) 2016;35:1558-63.

65. Szanton SL, Alfonso YN, Leff B, et al. Medicaid cost savings of a preventive home visit program for disabled older adults. J Am Geriatr Soc 2018;66: 614-20.
66. Rotenberg J, Kinosian B, Boling P, Taler G. Homebased primary care: beyond extension of the independence at home demonstration. J Am Geriatr Soc. 2018;66:812-817.

67. DeJonge KE, Taler G, Boling PA. Independence at home: community-based care or older adults with severe chronic illness. Clin Geriatr Med 2009;25: 155-69. 